\title{
Cyclosporine in the Management of Impetigo Herpetiformis: A Case Report and Review of the Literature
}

\author{
Aikaterini Patsatsi ${ }^{a} \quad$ Theodoros D. Theodoridis $^{b}$ Dimitrios Vavilis ${ }^{b}$ \\ Vasilios Tzevelekis $^{b} \quad$ Aikaterini Kyriakou $^{a}$ Dimitrios Kalabalikis ${ }^{a}$ \\ Dimitrios Sotiriadis ${ }^{a}$ \\ ${ }^{\mathrm{a}}$ 2nd Department of Dermatology and Venereology, and ${ }^{\mathrm{b}}$ 1st Department of Obstetrics \\ and Gynecology, Aristotle University School of Medicine, Papageorgiou Hospital, \\ Thessaloniki, Greece
}

\section{Key Words}

Cyclosporine $\cdot$ Herpetiformis $\cdot$ Impetigo $\cdot$ Psoriasis $\cdot$ Pustular, psoriasis

\begin{abstract}
A 27 -year-old female, gravida 1, para 0 , in week 22 of pregnancy, presented with an eruption consisting of annular erythematosquamous plaques with an active polycyclic elevated border comprised of superficial micropustules. Clinical and histological features were typical of impetigo herpetiformis $(\mathrm{IH})$. Systemic steroids resulted in an unstable condition, with no resolution of lesions. Resistance to the above therapeutic scheme served as a stimulus to discuss the use of cyclosporine as a therapeutic option in this condition. Reviewing the limited literature, cyclosporine seems to serve not as a monotherapy in the management of IH but as an additional medication, in order to achieve a stable course of the disease and avoid high doses of systemic steroids.
\end{abstract}

\section{Introduction}

Impetigo herpetiformis $(\mathrm{IH})$ is a rare dermatosis of pregnancy. There is a continuing debate whether it represents a form of pustular psoriasis triggered by the pregnancy status or just an entity itself [1-4]. The natural course of IH is commonly resolved in the postpartum period. The major difficulty remains handling the disease during pregnancy, especially when there is no response to systemic steroids. Resistance to the steroid scheme served as a 
stimulus to consequently discuss the use of cyclosporine as a therapeutic option for this condition.

\section{Case Report}

A 27-year-old female, gravida 1, para 0 , in week 22 of pregnancy, presented with an eruption consisting of annular erythematosquamous plaques with an active polycyclic elevated border comprised of superficial micropustules. Lesions were pruritic and widely distributed on the face, trunk and extremities (fig. 1, fig. 2).

The patient had had similar lesions in the past, with flare-ups and remissions since adolescence. A family history of psoriasis was also reported. Her mother and grandmother had a long-standing history of plaque-type psoriasis. Histology revealed a subcorneal collection of neutrophils, a psoriasiform epidermis and perivascular infiltration of lymphocytes and a few neutrophils in the dermis, typical features of pustular psoriasis (fig. 3). Direct immunofluorescence of perilesional skin with C3, IgG, IgA and IgM was negative.

The initial treatment decision was to avoid any systemic regimen and attempt to control the disease flare-up with topical steroids and emollients. There was no response and the patient, having generalized lesions, was admitted to the Obstetrics Department. Systemic steroids, at an initial dose of prednisolone $60 \mathrm{mg} /$ day for 3 weeks failed to control the disease and a partial response was achieved only at a dose of $80 \mathrm{mg} /$ day. Eight days after this partial improvement, new pustular lesions presented on the forehead, chest and buttocks. At this time point, week 27 of pregnancy, cyclosporine at a dose of $4 \mathrm{mg} / \mathrm{kg}$ body weight was added in order to prevent the development of new lesions and to help tapering from high steroid dosages.

An initial response with no further eruptive pustules was observed and the eruption remained stable for almost 1 month. Prednisolone was tapered to a minimum of $15 \mathrm{mg} /$ day and in combination with cyclosporine served as a stable regimen until the day of cesarean section, in week 32 of gestation. A healthy preterm male, 1,590 g, was born. Throughout the time of hospitalization, all laboratory exams, including full blood count, calcium, glucose, albumins, progesterone levels and electrolytes were unremarkable. Blood pressure was within normal limits. Ophthalmologic examinations were performed every week. Sonography of the fetus did not reveal any abnormalities.

Three weeks after delivery, showing no signs of improvement, cyclosporine tapering and the addition of methotrexate at a dose of $15 \mathrm{mg}$ subcutaneously per week was decided. The patient presented with only residual hyperpigmentation 2 months later.

\section{Discussion}

IH typically presents during the third trimester of pregnancy and resolves during the postpartum period [5]. It is a rare pustular dermatosis related to pregnancy with no more than 200 reported cases up to now [6]; it may recur in future pregnancies or with menstrual exacerbation [5]. In a significant number of cases, a history of psoriasis is well documented. It is a matter of debate whether it represents a pustular form of psoriasis or a separate entity related to pregnancy in cases when there is no personal or family history of psoriasis [3], when the lesions clear during the postpartum period and never rebound [2], or when they recur in subsequent pregnancies $[1,4]$. 
Patsatsi et al.: Cyclosporine in the Management of Impetigo Herpetiformis: A Case Report and Review of the Literature

Pathogenesis remains unclear for those who consider IH a separate entity. A possible triggering role in the onset of the disease is attributed to high levels of progesterone during the last trimester of pregnancy, low levels of calcium and reduced levels of epidermal skinderived antileukoproteinase activity implicated in the formation of epidermal pustules [5].

Clinically, IH presents with erythematous plaques bordered by tiny pustules in a herpetiform pattern. The centrifugal distribution of micropustules may spread all over the body and evolves into desquamation and subsequent hyperpigmentation. Histology is characterized by the presence of subcorneal spongiform pustules, parakeratosis and psoriasiform hyperplasia of the epidermis, all findings of pustular psoriasis. Absence of a perivascular infiltrate by eosinophils and of necrotic keratinocytes differentiates IH from acute generalized exanthematous pustulosis.

Despite the typical micropustules of IH, differential diagnosis may include autoimmune bullous diseases, like herpes gestationis, IgA pemphigus or linear IgA dermatosis. Histology and direct immunofluorescence have a critical role in distinguishing the above-mentioned entities. In many cases of IH, both mother and fetus are threatened. Maternal complications may be seen in unrecognized and unmonitored cases and consist of delirium, tetany due to hypocalcemia and convulsions. More severe is the impact on the fetus, mainly due to placental insufficiency. The major fetal risks are stillbirth, neonatal death and fetal abnormalities [5].

Systemic corticosteroids are considered the gold standard in the treatment of $\mathrm{IH}$, although their efficacy in the control of the disease varies. The most common scheme is with prednisolone at a dosage of $15-30 \mathrm{mg} /$ day, which may be increased to $80 \mathrm{mg} /$ day in refractory cases. Prednisolone, though nonteratogenic, has been associated in a limited number of cases with macrosomia, gestational diabetes and premature rupture of the membranes [7].

Cyclosporine has been administered in 13 patients with IH in the literature [6-17]. Reviewing the above-mentioned cases, in 12 out of 14 cases, including ours, cyclosporine was not used as a monotherapy in the treatment of IH but in combination with systemic corticosteroids (table 1). Prednisolone dosage was between 20 and $80 \mathrm{mg} /$ day. Fluocortolone and dexamethasone were used in 2 patients. Cyclosporine was administered at a dosage of $2-7.5 \mathrm{mg} / \mathrm{kg} /$ day. It is of interest that in only 1 case a complete resolution was achieved before delivery. The outcome of the combined scheme (prednisolone + cyclosporine) was a stable condition (3/14), a partial response (3/14) or a marked improvement $(4 / 14)$. Four of the cases were resistant to therapy and regression was observed after delivery. In conclusion, in 10 out of 14 cases (71.4\%) cyclosporine helped to achieve control of the disease, not a clearance of the lesions.

Despite placental transfer, cyclosporine seems to be rather safe. Children exposed in utero to cyclosporine have been shown to have normal renal function. Use of the lowest active dose and careful monitoring of the fetus is advisable, though, as there is still a weak possibility of early rupture of the membranes [18]. In the majority of $\mathrm{IH}$ cases, total regression of lesions must be expected after delivery and moreover, if there is persistence, with an alternative regimen, such as methotrexate [19] or infliximab [16]. In our patient, 3 weeks after cesarean section, methotrexate at a dose of $15 \mathrm{mg}$ subcutaneously was proposed, resulting in a complete clearance.

In conclusion, cyclosporine in the treatment of IH seems to represent an alternative therapeutic option when there is resistance to systemic corticosteroids or a steroid-sparing agent in order to taper high dosages of steroids. It must also be considered in addition to corticosteroids, in order to control flare-ups of the disease. 
Patsatsi et al.: Cyclosporine in the Management of Impetigo Herpetiformis: A Case Report and Review of the Literature

\section{Disclosure Statement}

The authors have no conflict of interest to declare.

\section{References}

1 Beveridge GW, Harkness RA, Livingstone JR: Impetigo herpetiformis in two successive pregnancies. Br J Dermatol 1966;78:106-112.

2 Lotem M, Katzenelson V, Rotem A, Hod M, Sandbank M: Impetigo herpetiformis: a variant of pustular psoriasis or a separate entity? J Am Acad Dermatol 1989;20:338-341.

-3 Pierard GE, Pierard-Franchimont C, de la Brassinne M: Impetigo herpetiformis and pustular psoriasis during pregnancy. Am J Dermatopathol 1983;5:215-220.

4 Wolf Y, Groutz A, Walman I, Luxman D, David MP: Impetigo herpetiformis during pregnancy: case report and review of the literature. Acta Obstet Gynecol Scand 1995;74:229-232.

5 Roth MM: Pregnancy dermatoses: diagnosis, management, and controversies. Am J Clin Dermatol 2011;12:25-41.

6 Hazarika D: Generalized pustular psoriasis of pregnancy successfully treated with cyclosporine. Indian J Dermatol Venereol Leprol 2009;75:638.

7 Edmonds EV, Morris SD, Short K, Bewley SJ, Eady RA: Pustular psoriasis of pregnancy treated with ciclosporin and high-dose prednisolone. Clin Exp Dermatol 2005;30:709-710.

-8 Arslanpence I, Dede FS, Gokcu M, Gelisen 0: Impetigo herpetiformis unresponsive to therapy in a pregnant adolescent. J Pediatr Adolesc Gynecol 2003;16:129-132.

-9 Brightman L, Stefanato CM, Bhawan J, Phillips TJ: Third-trimester impetigo herpetiformis treated with cyclosporine. J Am Acad Dermatol 2007;56:S62-S64.

10 Finch TM, Tan CY: Pustular psoriasis exacerbated by pregnancy and controlled by cyclosporin A. Br J Dermatol 2000;142:582-584.

11 Imai N, Watanabe R, Fujiwara H, Ito M, Nakamura A: Successful treatment of impetigo herpetiformis with oral cyclosporine during pregnancy. Arch Dermatol 2002;138:128-129.

12 Kura MM, Surjushe AU: Generalized pustular psoriasis of pregnancy treated with oral cyclosporin. Indian J Dermatol Venereol Leprol 2006;72:458-459.

13 Lakshmi C, Srinivas CR, Paul S, Chitra TV, Kanchanamalai K, Somasundaram LS: Recurrent impetigo herpetiformis with diabetes and hypoalbuminemia successfully treated with cyclosporine, albumin, insulin and metformin. Indian J Dermatol 2010;55:181-184.

Raddadi AA, Baker DZ: Cyclosporin and pregnancy. Br J Dermatol 1999;140:1197-1198.

Samieh-Tucker A, Rupasinghe M: Anaesthesia for caesarean section in a patient with acute generalised pustular psoriasis. Int J Obstet Anesth 2007;16:375-378.

Sheth N, Greenblatt DT, Acland K, Barker J, Teixeira F: Generalized pustular psoriasis of pregnancy treated with infliximab. Clin Exp Dermatol 2009;34:521-522.

$\checkmark 17$ Valdes E, Nunez T, Pedraza D, Munoz H: Recurrent impetigo herpetiformis: successfully managed with ciclosporine. Report of one case (in Spanish). Rev Med Chil 2005;133:1070-1074.

18 Bar OB, Hackman R, Einarson T, Koren G: Pregnancy outcome after cyclosporine therapy during pregnancy: a meta-analysis. Transplantation 2001;71:1051-1055.

$>19$ Luewan S, Sirichotiyakul S, Tongsong T: Recurrent impetigo herpetiformis successfully treated with methotrexate: a case report. J Obstet Gynaecol Res 2011;37:661-663. 
Patsatsi et al.: Cyclosporine in the Management of Impetigo Herpetiformis: A Case

Report and Review of the Literature

Table 1. Published cases of IH treated with cyclosporine

\begin{tabular}{|c|c|c|c|c|c|}
\hline $\begin{array}{l}\text { Reference } \\
\text { first author }\end{array}$ & Case & $\begin{array}{l}\text { Week of } \\
\text { pregnancy } \\
\text { at onset } \\
\text { of disease }\end{array}$ & $\begin{array}{l}\text { Steroid dosage } \\
\mathrm{mg} / \text { day }\end{array}$ & $\begin{array}{l}\text { Cyclosporine } \\
\mathrm{mg} / \mathrm{kg} / \text { day }\end{array}$ & Outcome \\
\hline Raddadi [14] & 1 & 29th & - & 3.5 & marked improvement \\
\hline Finch [10] & 2 & 25th & 40 & 3 & marked improvement \\
\hline Imai [11] & 3 & 27 th & 45 & 3 & marked improvement \\
\hline Arslanpence [8] & 4 & 27th & fluocortolone 50 & 5 & no response \\
\hline Edmonds [7] & 5 & 18th & $\begin{array}{l}\text { 40; flare-ups at doses } \\
<30\end{array}$ & 2.5 increased to 3 & stable condition \\
\hline Valdes [17] & 6 & 16th & 60 tapered to $<20$ & 2.5 & $\begin{array}{l}\text { regression of lesions } \\
\text { after delivery }\end{array}$ \\
\hline Kura [12] & 7 & 12th & 60 tapered to $<20$ & 2 & partial response \\
\hline Brightman [9] & 8 & 30th & 60 & 4 & marked improvement \\
\hline $\begin{array}{l}\text { Samieh-Tucker } \\
{[15]}\end{array}$ & 9 & 25 th & dexamethasone & $\begin{array}{l}\text { exact dose not } \\
\text { reported }\end{array}$ & no response \\
\hline Sheth [16] & 10 & 20th & 60 & 7.5 & $\begin{array}{l}\text { persistence for } 7 \\
\text { weeks after delivery - } \\
\text { initiation of infliximab }\end{array}$ \\
\hline Hazarika [6] & 11 & 20th & 30 & 3 & partial response \\
\hline Hazarika [6] & 12 & 28th & $\begin{array}{l}\text { 40; discontinued when } \\
\text { switched to cyclosporine } \\
\text { (due to severe gastritis) }\end{array}$ & 3 & complete resolution \\
\hline Lakshmi [13] & 13 & 26th & 50 & 3 & partial response \\
\hline Our case & 14 & 22nd & 80 tapered to 15 & 4 & stable condition \\
\hline
\end{tabular}

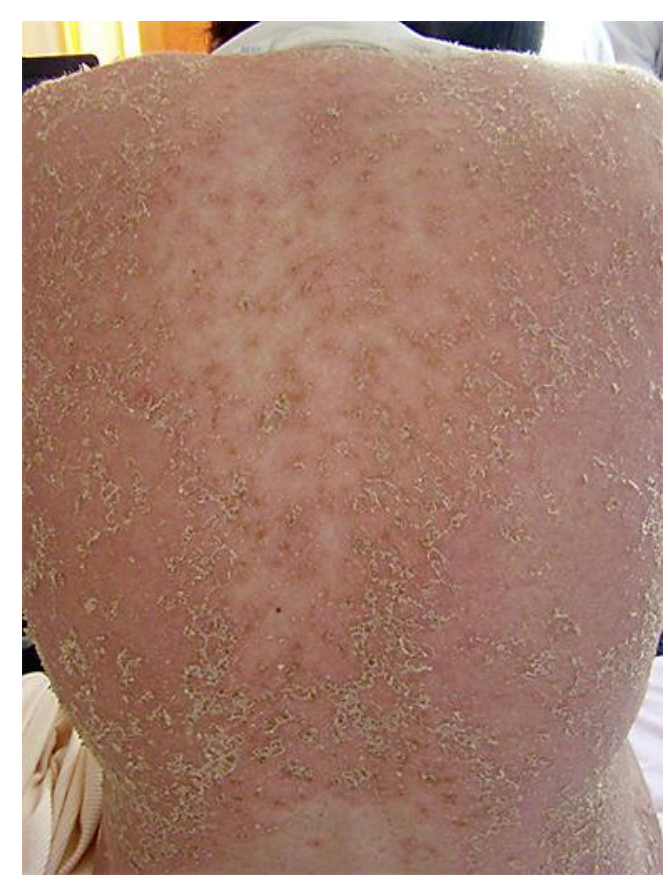

Fig. 1. Annular erythematosquamous plaques with an active polycyclic elevated border. 


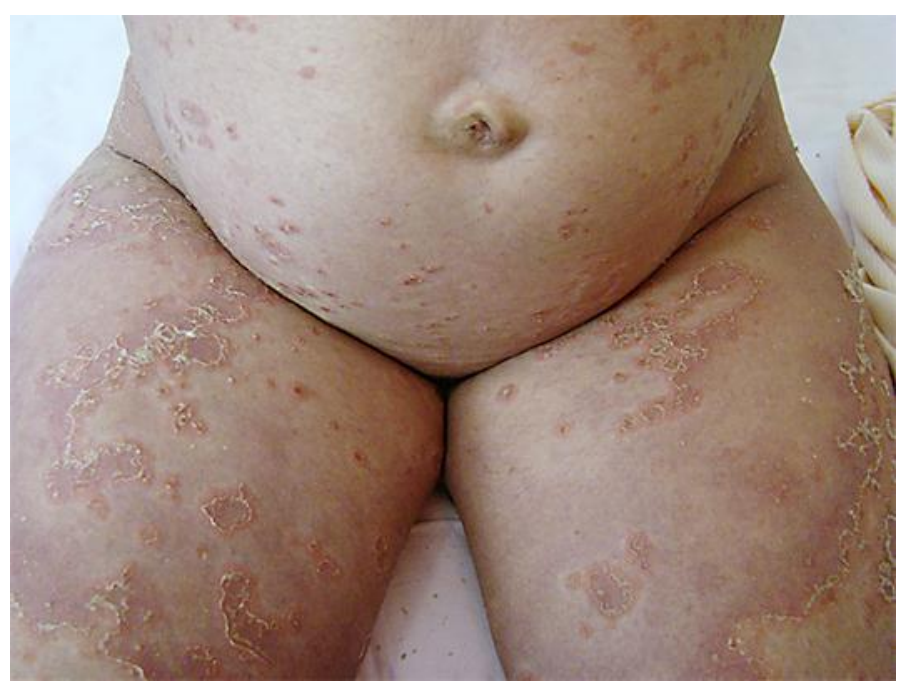

Fig. 2. Erythematosquamous lesions with peripheral micropustules on the trunk.

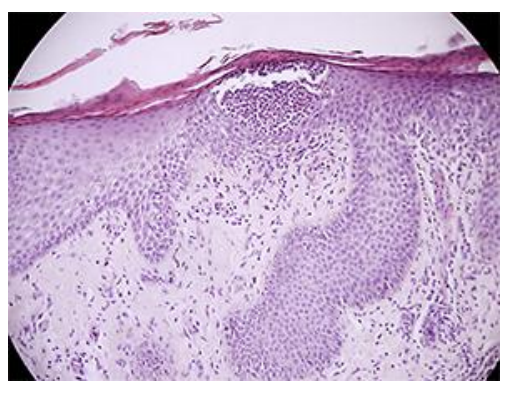

Fig. 3. Subcorneal collection of neutrophils, psoriasiform epidermis. HE. $\times 25$. 